\title{
Tuberculose em cuidados primários: um caso clínico
}

Liliana Castanheira, ${ }^{1-2}$ Raquel Olivença, ${ }^{2}$ Maria Fernanda Lima ${ }^{3}$

\section{RESUMO}

Introdução: A tuberculose permanece um problema de saúde global que afeta milhares de pessoas todos os anos e continua a ser a segunda maior causa de morte por doença infeciosa a nível mundial. O caso clínico apresentado relembra que a tuberculose pulmonar é uma hipótese de diagnóstico nos doentes com sintomatologia persistente do foro respiratório.

Descrição do caso: Homem, 31 anos de idade, saudável, que recorreu a consulta de medicina geral e familiar por quadro, com quatro dias de evolução, de febre, mialgias, arrepios, tosse com expetoração mucopurulenta, cansaço e desconforto na região mediana do hemitórax esquerdo, mas sem dispneia. Foi medicado com paracetamol e pedida radiografia do tórax. A radiografia do tórax apresentava imagem de densificação parenquimatosa pulmonar do lobo superior esquerdo, com sinal de broncograma aéreo; perante este resultado foi medicado com amoxicilina e ácido clavulânico. Após seis dias de antibiótico iniciou sudorese noturna, mantendo restante sintomatologia e sem alterações na nova radiografia do tórax. Contactou-se Centro de Diagnóstico Pneumológico da área, onde o pneumologista sugeriu exame bacteriológico direto e cultural de micobactérias e repetição de radiografia. Após cumprir antibioterapia prescrita, por ausência de melhoria da clínica, iniciou levofloxacina. Após cinco dias apresentou o resultado do exame bacteriológico direto, sendo que as duas primeiras amostras eram negativas e a terceira identificou Enterobacter cloacae. Optou-se por manter levofloxacina. No entanto, finalizada a medicação, por ausência de melhoria do quadro clínico decidiu-se pedir nova colheita de expetoração para exame bacteriológico direto e exame cultural. Passados 35 dias da primeira consulta, o resultado do segundo exame bacteriológico direto à expetoração apresentava a primeira amostra positiva para bacilos ácido álcool resistentes, pelo que o doente foi reencaminhado para o Centro de Diagnóstico Pneumológico local, onde realizou exames adicionais e iniciou terapêutica tuberculostática.

Palavras-chave: Tuberculose pulmonar; Médico de família; Diagnóstico.

\section{INTRODUÇÃO}

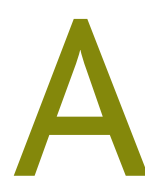

tuberculose permanece, na atualidade, um problema de saúde global que afeta milhares de pessoas todos os anos e continua a ser a segunda maior causa de morte por doença infeciosa a nível mundial, a seguir ao vírus da imunodeficiência humana (VIH). Declarada pela Organização Mundial da Saúde (OMS) como uma emergência mundial, a tuberculose é uma doença contagiosa causada pela bactéria Mycobacterium tuberculosis. ${ }^{1}$

Em Portugal, nos últimos 10 anos, a taxa de incidência de casos de tuberculose diminuiu cerca de $40 \%$, com

1. Professora Auxiliar. Escola de Ciências e Tecnologias da Saúde, Universidade Lusófona.

2. Médica Interna de Medicina Geral e Familiar. Unidade de Saúde Familiar do Dafundo. 3. Médica Assistente de Medicina Geral e Familiar. Unidade de Saúde Familiar do Dafundo. valores abaixo dos 20/100.000 habitantes. A principal manifestação clínica é a tuberculose pulmonar $(71,3 \%) .^{2} \mathrm{O}$ distrito de Lisboa continua a ser um dos que tem maior incidência desta patologia, com uma taxa entre 22/100.000 e 31/100.000, um valor considerado como intermédio pela OMS. ${ }^{1} \mathrm{~A}$ incidência é maior no sexo masculino (64\%) e na faixa etária entre os 35 e 54 anos. Relativamente ao Agrupamento de Centros de Saúde de Lisboa Ocidental eVale do Tejo, em 2016 a taxa de incidência de tuberculose foi de 15/100.000, bastante inferior à de Lisboa. ${ }^{2-4}$

A tuberculose é mais frequente em indivíduos imunocomprometidos, estando associada a algumas comorbilidades, principalmente à infeção pelo VIH. Existem alguns fatores de risco social para a tuberculose, nomeadamente, o tabagismo, o consumo de drogas ilícitas e o abuso do álcool. ${ }^{1}$ 
Os autores relatam um caso clínico de tuberculose pulmonar de diagnóstico desafiante, num doente jovem fumador, sem patologia conhecida, sem contexto epidemiológico, inicialmente sem clínica evidente, mas com avaliação radiológica suspeita e, no entanto, com exames culturais de expetoração inicialmente negativos. Perante este quadro, foi o elevado nível de suspeição do médico de família que permitiu fazer o diagnóstico.

O relato deste caso clínico surge pela importância da tuberculose enquanto doença infetocontagiosa, pelo facto de a incidência da tuberculose estar a baixar, o que leva a que muitas vezes seja esquecida como hipótese de diagnóstico; pelo facto de adicionalmente os sintomas iniciais da infeção serem na maioria das vezes inespecíficos, podendo ser desvalorizados pelo doente e retardar a procura de cuidados; por fim, porque evidencia as dificuldades de diagnóstico da tuberculose ao nível dos cuidados primários pela limitação dos recursos disponíveis.

\section{DESCRIÇÃO DO CASO}

Homem, 31 anos de idade, caucasiano, trabalhador numa gráfica, natural e residente no Dafundo, em Oeiras, casado, pertencente a uma família nuclear alargada, vive com esposa, filha e mãe. É fumador de quatro unidades maço/ano.

Sem antecedentes pessoais (patológicos ou cirúrgicos) relevantes, sem alergias conhecidas, nega hábitos alcoólicos ou consumo de drogas de abuso e contexto epidemiológico. O plano de vacinação encontrava-se atualizado.

Em 26/01/2016 recorreu à consulta do dia, na Unidade de Saúde do concelho de Oeiras, por febre há quatro dias, com temperatura máxima axilar de $39{ }^{\circ} \mathrm{C}$, acompanhado de mialgias, arrepios, tosse com expetoração mucopurulenta e cansaço; refere também sentir desconforto na região mediana do hemitórax esquerdo, negando dispneia e contacto com doentes com patologia respiratória. Ao exame objetivo é de salientar a palpação de crepitação inspiratória na região mediana do hemitórax esquerdo e à auscultação pulmonar apresentava murmúrio vesicular mantido, sem ruídos adventícios. Nesta primeira consulta foi pedida radiografia do tórax $(\mathrm{Rx})$ e o utente foi medicado com paracetamol $1000 \mathrm{mg}$, um comprimido três vezes ao dia. $\mathrm{O}$

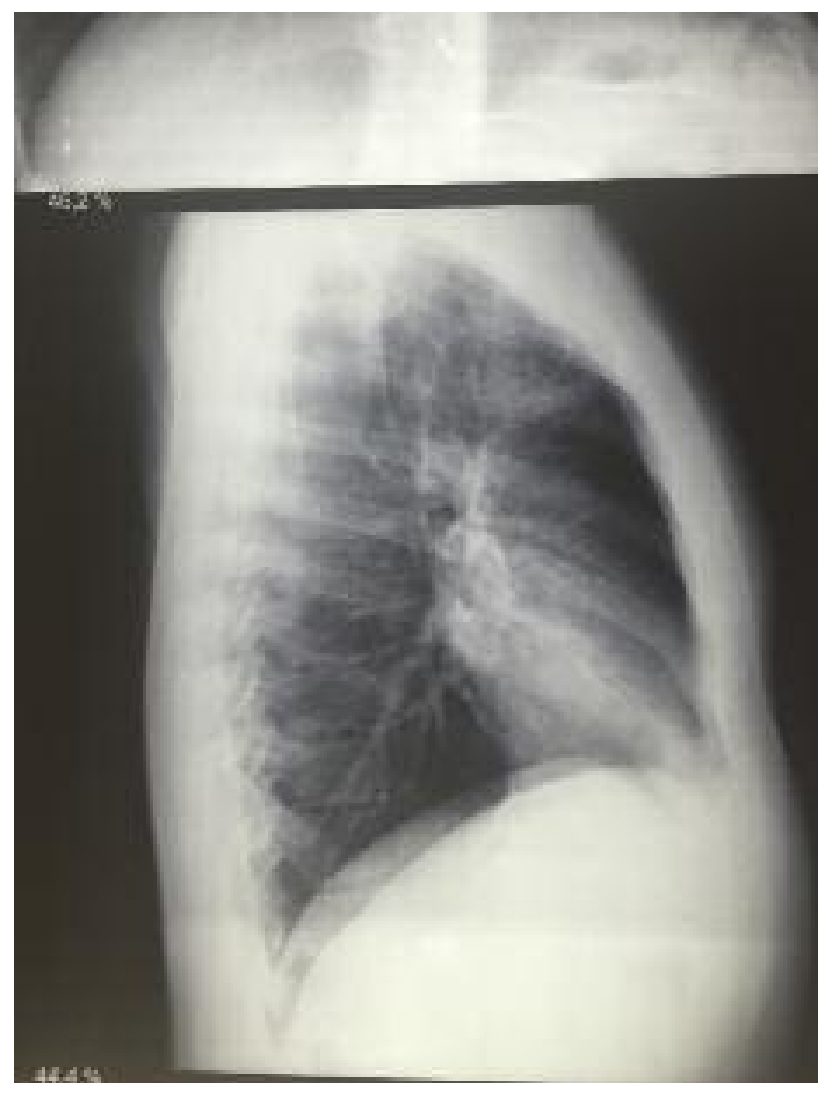

Figura 1. Primeira radiografia do tórax.

$\mathrm{Rx}$ (Figura 1) apresentava uma imagem de densificação parenquimatosa do lobo superior esquerdo com sinal de broncograma aéreo por processo pneumónico; perante este resultado foi medicado com amoxicilina $875 \mathrm{mg}$, mais ácido clavulânico $125 \mathrm{mg}$, um comprimido duas vezes ao dia, durante oito dias.

Por manutenção de quadro clínico após seis dias de antibiótico fez novo Rx do tórax.

Em 03/02/2016 o doente voltou à consulta para reavaliação, referindo adicionalmente sudorese noturna, mantendo restante quadro clínico, com exame objetivo e Rx sobreponíveis aos anteriores. Neste dia contactou-se o Centro de Diagnóstico Pneumológico da área (CDP), onde o pneumologista sugeriu realização de exame bacteriológico direto e cultural de micobactérias e repetição de Rx. Não havendo resolução do quadro, o CDP indicou que se deveria pedir tomografia computorizada e iniciar levofloxacina. Adicionalmente aos exames recomendados pelo pneumologista, o médico de família pediu análises [hemograma, velocidade de 
sedimentação (VS), creatinina, anticorpos VIH1 e 2 e proteína C reativa $(\mathrm{PCR})$ ]. Da avaliação laboratorial destacou-se VS 62 e PCR 1,1mg/dl, com serologias negativas para VIH.

Em 10/02/2016 foi reavaliado, referindo sentir-se melhor, mas mantendo tosse com expetoração mucopurulenta e desconforto na região mediana do hemitórax esquerdo, se bem que menos intenso, negando suores noturnos ou febre, mostrou Rx, que era sobreponível ao anterior, tendo-se decidido iniciar levofloxacina 500mg um comprimido por dia.

Em 15/02/2016 foi reavaliado, referindo novamente suores noturnos, mantendo tosse com expetoração mucopurulenta, sentindo desconforto no hemitórax muito esporadicamente, com auscultação pulmonar sem alterações. Os resultados do exame bacteriológico direto eram negativos nas duas primeiras amostras, tendo-se identificado na terceira amostra Enterobacter cloacaesensível a ciprofloxacina, cefotaxima, cotrimoxazol e resistente a amoxicilina. Pediu-se novamente hemograma, VS, PCR e Rx, sendo os resultados sobreponíveis aos anteriores, apenas com aumento de PCR para $2,8 \mathrm{mg} / \mathrm{dl}$.

Em 22/02/2016, por ausência de melhoria do quadro clínico, decidiu-se repetir colheita de expetoração para exame bacteriológico direto e cultural com pesquisa de micobactérias.

Em 01/03/2016 (35 dias após a primeira consulta) trouxe resultado do segundo exame bacteriológico direto à expetoração, em que a primeira amostra identificou bacilos álcool resistentes; o Rx do tórax mantinha densificação apical esquerda. O doente foi encaminhado para o CDP, onde foi instituída terapêutica tuberculostática (rifampicina, isoniazida, pirazinamida, etambutol, pirodixina) e em que a toma é de observação direta no centro de saúde, sendo seguido em consultas com periodicidade mensal no CDP.

Por indicação do CDP, todos os familiares que residem na mesma casa com o doente fizeram o rastreio, assim como os colegas de trabalho.

\section{COMENTÁRIO}

Apesar de nos últimos anos ter ocorrido uma diminuição da incidência de tuberculose pulmonar, segundo a OMS os distritos de Lisboa, Porto, Setúbal e região do Algarve apresentam uma incidência intermédia. ${ }^{1}$
As manifestações clínicas da tuberculose geralmente são sistémicas e inespecíficas, mimetizando outras patologias, o que pode dificultar o diagnóstico. Relativamente à tuberculose pulmonar, as manifestações clínicas frequentes são tosse, febre, dor torácica, cansaço, perda de peso/anorexia, sudorese noturna e hemoptises. ${ }^{5} \mathrm{À} \mathrm{exceção} \mathrm{da} \mathrm{hemoptise,} \mathrm{todas} \mathrm{as} \mathrm{outras} \mathrm{manifes-}$ tações são inespecíficas, não sugerindo à partida a hipótese de tuberculose. Ao exame objetivo, os doentes com tuberculose ativa podem ter sons respiratórios anormais, especialmente nos lobos superiores ou áreas envolvidas e podem ser auscultados fervores ou sinais de respiração brônquica, indicando a consolidação de pulmão. ${ }^{6}$ Nos casos em que há hemoptises ou em que os sintomas respiratórios gerais persistem por duas ou três semanas devem-se iniciar os procedimentos de diagnóstico de tuberculose. ${ }^{5} \mathrm{O}$ diagnóstico é confirmado se houver identificação do Mycobacterium tuberculosis em exame cultural ou se o exame direto e o teste de amplificação de ácidos nucleicos (TAAN) forem positivos..$^{5-6} \mathrm{~A}$ investigação de infeção ativa inclui realização de Rx do tórax, três amostras de expetoração colhidas para avaliação de bacilos álcool-ácido resistentes (BAAR), TAAN, hemograma completo e ionograma. ${ }^{5}$ Como referido, a cultura da expetoração é o golden standard para o diagnóstico de tuberculose; no entanto, dependendo dos sistemas de meio de cultura, o resultado pode demorar uma a três semanas quando o meio de cultura é líquido ou quatro a oito semanas em meio sólido. ${ }^{5}$ O TAAN deve ser realizado em pelo menos uma amostra respiratória, quando o diagnóstico estiver sendo considerado, podendo acelerar o diagnóstico em casos de esfregaço negativo e pode ser útil para identificar as micobactérias não tuberculosas. ${ }^{7}$ A tomografia computorizada (TC) do tórax, embora não seja realizada de forma rotineira, pode ser usada para excluir outras patologias, nomeadamente neoplasias. ${ }^{6}$ Recomenda-se que todos os doentes portadores de tuberculose devam ser testados para oVIH até dois meses depois do diagnóstico. ${ }^{7}$

Segundo o Manual de Tuberculose, da Direção-Geral da Saúde, face à suspeita de tuberculose pulmonar é uma boa prática a colheita de duas amostras de expetoração no mesmo dia, com envio imediato ao laboratório. Perante um resultado negativo deve-se insistir na colheita de mais amostras ou mesmo avançar para 
técnicas invasivas de diagnóstico, como a broncofibroscopia. $^{5}$

Ao nível dos cuidados primários, o sistema informático apenas disponibiliza o pedido de Rx do tórax; a colheita de expetoração para BAAR e o exame cultural têm de ser pedidos manualmente, sendo comparticipados. O TAAN pode ser também pedido manualmente, mas tem um custo muito alto para o doente, pois não é comparticipado quando prescrito pelo médico de família.

O caso clínico apresentado refere-se a um caso confirmado de tuberculose num doente do sexo masculino, jovem, saudável, em que o tabagismo é único fator de risco, sem contexto epidemiológico e sem comorbilidades conhecidas, nomeadamente infeção por VIH. Numa primeira avaliação o doente apresentava um quadro clínico muito similar a uma infeção aguda do sistema respiratório, não se tendo colocado a tuberculose como hipótese diagnóstica. A localização das lesões no $\mathrm{Rx}$, juntamente com a sudorese noturna, veio levantar a suspeita de tuberculose; no entanto, os resultados do primeiro exame direto da expetoração foram negativos para Mycobacterium tuberculosis. O facto de o doente não ter melhorado com instituição de terapêutica para a pneumonia e a persistência dos sintomas fez com que se mantivesse a suspeita e se repetisse o exame direto à expetoração, tendo permitido o diagnóstico. A hipótese de neoplasia não foi colocada, justificando o facto de não se ter pedido tomografia computorizada do pulmão, pois o doente é jovem sem antecedentes familiares de neoplasia e apresentava um quadro clínico muito sugestivo de infeção.

Em Portugal, o tempo médio desde o início dos sintomas até ao diagnóstico são 104 dias; no caso clínico descrito foi de 39 dias. Considerando que temos um doente jovem, previamente saudável, pode considerar-se que foi um diagnóstico rápido. ${ }^{1}$

A rapidez de diagnóstico é essencial ao combate da tuberculose, pois esta é uma doença altamente contagiosa. Este caso clínico mostra que não é fácil diagnosticar tuberculose em cuidados primários de uma forma rápida, de forma a evitar o contágio. Este problema decorre não só das características da doença como do facto dos exames à expetoração não estarem disponíveis no sistema informático, os resultados do exame cultural demorarem no mínimo três semanas e a TAAN não ser comparticipada.
O caso clínico apresentado evidencia que a tuberculose pulmonar pode ser uma hipótese de diagnóstico num doente jovem, saudável, quando temos persistência de clínica sugestiva, sendo fundamental o médico de família ter esta hipótese em consideração. É também importante realçar que, quando o médico de família suspeita de tuberculose pulmonar num doente com resultados negativos no BAAR, este exame deve ser repetido.

A discussão do diagnóstico de tuberculose pulmonar neste caso clínico contribui para incrementar o conhecimento dos profissionais de saúde neste tema, de forma a responder aos desafios propostos pela Direção-Geral da Saúde. ${ }^{2}$

\section{REFERÊNCIAS BIBLIOGRÁFICAS}

1. Direção-Geral da Saúde. Portugal: infeção VIH/SIDA e tuberculose em números (Programa Nacional para a Infeção VIH/SIDA). Lisboa: DGS; 2015.

2. Direção-Geral da Saúde. Portugal - Tuberculose em Portugal: desafios e estratégias 2018. Lisboa: DGS; 2018.

3. Unidade Saúde Pública. Relatório de atividades 2016. Oeiras: Agrupamento dos Centros de Saúde Lisboa Ocidental e Oeiras; 2017.

4. Monteiro Júnior JJ, Gaspar Al, Vilela H, Filipe R, Dinis AB. Plano local de saúde -ACES Lisboa Ocidental e Oeiras, 2014-2016 [Internet]. Oeiras: Agrupamento dos Centros de Saúde Lisboa Ocidental e Oeiras; 2014. Available from: https://www.arslvt.min-saude.pt/uploads/writer_file/ document/1034/Plano_Local_Sa_de_v4-_Vers_o_Final.pdf

5. González-Martín J, García-García JM, Anibarro L, Vidal R, Esteban J, Moreno S, et al. Documento de consenso sobre diagnóstico, tratamiento y prevención de la tuberculosis. Documento conjunto de la Sociedad Española de Enfermedades Infecciosas y Microbiología Clínica (SEIMC) y de la Sociedad Española de Neumología y Cirugía Torácica (SEPAR) [Consensus document on the diagnosis, treatment and prevention of tuberculosis]. Arch Bronconeumol. 2010;46(5):255-74. Spanish

6. Duarte R, Brito MC, Villar M, Correia AM. Manual de tuberculose e micobactérias não tuberculosas. Lisboa: Direção-Geral da Saúde; 2016.

7. BMJ Best Practice. Tuberculose pulmonary: diagnóstico passo a passo [homepage]. BM] Best Practice; 2018 [updated 2019 Mar]. Available from: https://bestpractice.bmj.com/topics/pt-br/165

\section{CONFLITO DE INTERESSES}

Os autores declaram não ter quaisquer conflitos de interesse.

\section{ENDEREÇO PARA CORRESPONDÊNCIA \\ Liliana Castanheira \\ E-mail: lilianacastanheira2@gmail.com \\ https://orcid.org/0000-0002-5902-3763}

Recebido em 01-08-2016

Aceite para publicação em 11-04-2018 


\section{ABSTRACT}

\section{TUBERCULOSIS IN PRIMARY CARE: A CLINICAL CASE}

Introduction: Tuberculosis is still an important health problem all over the world that affects thousands of people every year and it remains the second larger cause of death by the infectious disease worldwide. This clinical case reminds us that pulmonary tuberculosis can be a hypothesis in the diagnosis of patients with persistent respiratory symptoms.

Case description: Man, 31 years old, healthy, comes to our family medicine consult with a four-day case of fever, myalgia, chills, and persistent cough with purulent sputum, fatigue, and discomfort in the middle region of the left hemithorax but without dyspnea. He was first medicated with paracetamol and we ordered a chest x-ray. The x-ray showed an image of pulmonary parenchymal densification of the upper left lobe with air bronchogram signal and therefore the patient was treated with amoxicillin plus clavulanic acid. After six days of antibiotic, he presented a new onset of night sweat, keeping the remaining symptoms and with no changes in a most recent chest $x$-ray. We contacted the local Pulmonology Diagnostic Center, where the pulmonologist suggested a direct cultural and bacteriological examination of mycobacteria and a new x-ray. After fulfilling the prescribed antibiotic therapy, for lack of improvement of the clinic, we began a new treatment with levofloxacin. After five days we had the result of the direct bacteriological examination, the first two samples were negative and the third one identified Enterobacter cloacae. We chose to keep the antibiotic. After completing the therapy with levofloxacin, for lack of improvement, it was decided to request a new sputum collection for direct bacteriological examination and culture test. After 35 days of the first visit, new results of the second bacteriological examination were ready, in which the first sample was positive for acid-alcohol resistant bacillus, therefore the patient was forwarded to the Pulmonology Diagnostic Center, which conducted additional tests and started the tuberculostatic treatment.

Keywords: Pulmonary tuberculosis; Family doctor; Diagnosis. 